\title{
Recognizing the role of psychiatric comorbidities: a response to the Danish Colorectal Screening Program
}

This article was published in the following Dove Medical Press journal: Clinical Epidemiology

\section{Inayat Hussain Khan Tasnim Chowdhury}

Faculty of Medicine, St George's Hospital Medical School, London, UK
Correspondence: Inayat Hussain Khan Faculty of Medicine, St George's Hospital Medical School, Cranmer Terrace, London, SWI 7 ORE, UK Tel +447597827728 EmailmI506I3।@sgul.ac.uk

\section{Dear editor,}

We took great interest in the recent article by Thomsen et al $^{1}$ outlining factors which predicted adherence to follow-up diagnostic colonoscopy in the Danish Colorectal Screening Program. This is particularly relevant as colorectal cancer (CRC) is the second most common cause of cancer mortality worldwide. ${ }^{2}$ Evaluating factors which affect screening uptake and follow-up are pivotal to public health as early detection of cancer results in dramatically improved survival. ${ }^{3}$

In this study, Thomsen et al ${ }^{1}$ assessed comorbidity using the Charlson Comorbidity Index (CCI) score, single diagnoses, the number of in-hospital stays within the past year and looked at adherence following a positive fecal occult blood test (FOBT). The original article is detailed and provides a wealth of information aiding understanding of factors which may affect uptake of diagnostic colonoscopy. The CCI score that Thomsen et $\mathrm{al}^{1}$ used evaluated mainly physical comorbidities including myocardial infarction, congestive heart failure, peripheral vascular disease and cerebrovascular disease. We applaud the authors for identifying factors that affect adherence to diagnostic colonoscopy and we agree that severe comorbidity may affect uptake of colonoscopy following a positive FOBT.

There were, however, a number of important conditions, such as psychiatric comorbidities, which were not explored by this study. In a previous study by Kodl et $\mathrm{al},{ }^{4}$ the authors found that veterans with mental health diagnoses were significantly less likely to be screened for CRC than individuals with no mental health diagnoses. Similarly, another study found that those with a lower self-perceived mental health status had a reduced FOBT uptake for CRC screening, ${ }^{5}$ recognizing that individuals with poor mental health require additional support and follow-up from screening services.

In the current study by Thomsen et al, ${ }^{1} 38.4 \%$ of individuals did not want any further follow-up tests. We believe it is imperative that future studies evaluate participants' mental health status and preexisting psychiatric comorbidities to determine whether this is an attributing factor for not taking up colonoscopy. We, therefore, recommend that future studies should specifically outline psychiatric conditions and the number of diagnoses, incorporating this into the initial comorbidity score. Although it can be argued that poor mental health is a confounding variable, and will inevitably be present in those with chronic health conditions, we believe this further reinforces the need to determine the effect of psychiatric factors on nonadherence to follow-up measures. 
A huge barrier to accurate and prompt diagnosis in those with psychiatric comorbidities is differential access to opportunities for screening. This is likely due to a lack of integration between social health services and screening services. Attempting to determine the influence of psychiatric comorbidities is a difficult task, but one which we believe is essential to tackle inequalities and subsequently deliver effective health care to individuals with mental health conditions. We, therefore, hope that future studies will attempt to define psychiatric factors influencing uptake of follow-up diagnostic measures.

\section{Disclosure}

The authors report no conflicts of interest in this communication.

\section{References}

1. Thomsen MK, Rasmussen M, Njor SH, Mikkelsen EM. Demographic and comorbidity predictors of adherence to diagnostic colonoscopy in the Danish colorectal cancer screening program: a nationwide cross-sectional study. Clin Epidemiol. 2018;10:1733-1742.

2. Bray F, Ferlay J, Soerjomataram I, Siegel RL, Torre LA, Jemal A. Global cancer statistics 2018: GLOBOCAN estimates of incidence and mortality worldwide for 36 cancers in 185 countries. CA Cancer J Clin. 2018;68(6):394-424.

3. Selby JV, Friedman GD, Quesenberry CP, Weiss NS. A case-control study of screening sigmoidoscopy and mortality from colorectal cancer. $N$ Engl J Med. 1992;326(10):653-657.

4. Kodl MM, Powell AA, Noorbaloochi S, Grill JP, Bangerter AK, Partin MR. Mental health, frequency of healthcare visits, and colorectal cancer screening. Med Care. 2010;48(10):934-939.

5. Hategekimana C, Karamouzian M. Self-perceived mental health status and uptake of fecal occult blood test for colorectal cancer screening in Canada: a cross-sectional study. Int J Health Policy Manag. 2016;5(6): $365-371$.

Dove Medical Press encourages responsible, free and frank academic debate. The content of the Clinical Epidemiology 'letters to the editor' section does not necessarily represent the views of Dove Medical Press, its officers, agents, employees, related entities or the Clinical Epidemiology editors. While all reasonable steps have been taken to confirm the content of each letter, Dove Medical Press accepts no liability in respect of the content of any letter, nor is it responsible for the content and accuracy of any letter to the editor.

Clinical Epidemiology

\section{Publish your work in this journal}

Clinical Epidemiology is an international, peer-reviewed, open access, online journal focusing on disease and drug epidemiology, identification of risk factors and screening procedures to develop optimal preventative initiatives and programs. Specific topics include: diagnosis, prognosis, treatment, screening, prevention, risk factor modification,

Submit your manuscript here: https://www.dovepress.com/clinical-epidemiology-journa
Dovepress

systematic reviews, risk and safety of medical interventions, epidemiology and biostatistical methods, and evaluation of guidelines, translational medicine, health policies and economic evaluations. The manuscript management system is completely online and includes a very quick and fair peer-review system, which is all easy to use. 